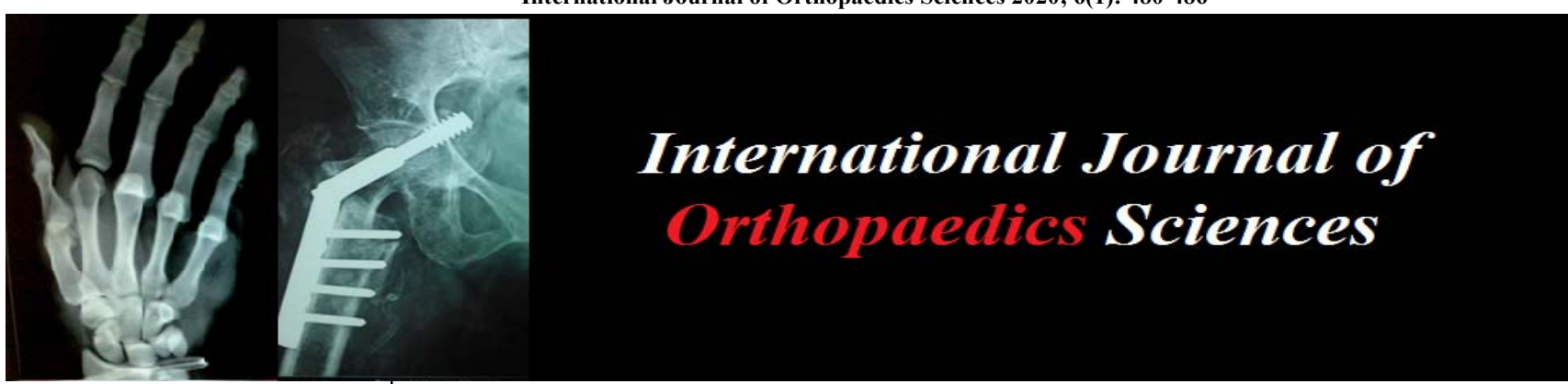

E-ISSN: 2395-1958

P-ISSN: 2706-6630

IJOS 2020; 6(1): 480-486

(C) 2020 IJOS

www.orthopaper.com

Received: 11-11-2019

Accepted: 15-12-2019

Vetrivel Chezian Sengodan Director and Professor, Institute of Orthopedics and Traumatology, Coimbatore Medical College and Hospital, Coimbatore, Tamil Nadu, India

Marimuthu Sivagnanam Assistant professor, Institute Of Orthopedics and Traumatology, Coimbatore Medical College and Hospital, Coimbatore, Tamil Nadu, India

Karthikeyan Kandasamy Junior resident, Institute of Orthopaedics and Traumatology, Coimbatore Medical College and Hospital, Coimbatore, Tamil Nadu, India
Corresponding Author: Vetrivel Chezian Sengodan Director and Professor, Institute of Orthopedics and Traumatology, Coimbatore Medical College and Hospital, Coimbatore, Tamil Nadu, India

\section{Impact of Tamil Nadu accident and emergency care initiative (TAEI) programme on orthopaedic emergency fixation: Lesson from Coimbatore for low income countries}

\author{
Vetrivel Chezian Sengodan, Marimuthu Sivagnanam and Karthikeyan \\ Kandasamy
}

DOI: https://doi.org/10.22271/ortho.2020.v6.i1i.1911

\section{Abstract}

Introduction: Tamil Nadu accounted for $10.1 \%$ of the road traffic accidents in India. In a view to reduce the mortality and morbidity of trauma patients the Government of Tamil Nadu have come with an innovative idea of "Tamil Nadu Accident and Emergency care Initiative (TAEI)" programme in 2016. This study done at our Institute of orthopaedics and traumatology, Coimbatore medical college hospital analysis the impact of TAEI on various aspects before and after its implementation.

Materials and Method: This is a comparative study and the study period was from January 2017 to November 2019. The emergency orthopaedic trauma patients treated before implementation of TAEI in 2017(January -November) was analysed with after implementation of TAEI in 2019(January November). We also compared the performance of the CMCHIS before and after the implementation of the TAEI programme.

Results: The total emergency surgeries done before the TAEI implementation in 2017 were 732 cases and after TAEI implementation in 2019 were 1053 patients. The total number of intramedullary interlocking nailing done in emergency orthopaedic theatre before and after TAEI was 5 and 155 cases respectively. The total number of external fixator done before and after TAEI was 119 and 184 respectively. The total number of beneficiaries from the CMCHIS before TAEI before and after TAEI was 558 and 975 respectively.

Conclusion: The TAEI programme is found to have a major impact on the emergency orthopaedic trauma care in various aspects and also helped in generating more fund for the Government of Tamil Nadu.

Keywords: trauma, emergency department, TAEI, CMCHIS, road traffic accident, orthopaedic trauma

\section{Introduction}

Hospitals are the most important component of the health system in developing countries and accounts for about $50 \%-80 \%$ of total health costs. Due to the increase in the number of automobile usage, the road traffic accidents are at steep raise nowadays. State crime records bureau of 2017 indicated that Tamil Nadu accounted for $10.1 \%$ of the total road traffic accidents fatalities in the country. A vehicular accident is reported every 3 minutes and a death reported every 10 minutes on our records. During 1998, nearly, 80,000 lives were lost and 330,000 people were injured ${ }^{[1]}$. With the coordinated efforts of various stakeholders such as police, health and transport officials, fatalities have dropped by $24.39 \%$ in 2018 . The future appears both daunting and challenging. It is estimated that from its present position of the ninth leading cause of deaths in India, trauma will move up to third position by 2020 . It also is estimated that in the developing countries more than 6 million will die and 60 million will be injured, or disabled, in the next 10 years ${ }^{[2]}$.

The Lancet Commission on Global Surgery, in its report, released in 2015, put forth a forceful argument in favour of strengthening the surgery infrastructure. The commission has identified three surgical conditions (i.e., peritonitis, compound fracture, and Caesarean section) as the 
bellwether procedures for which infrastructure should be made available ${ }^{[3]}$.

In 2015 the World Health Assembly adopted a resolution A68/31 for "Strengthening emergency and essential surgical care and anaesthesia" as a component of universal health coverage ${ }^{[4]}$. India is also a signatory to this resolution. For many years, public health has failed to look surgery as its integral part. It is time to change this paradigm in India. The four lenses that are needed to view the various dimensions of surgical access are that of 1) Geographical access and distance from a functioning hospital, 2) the availability of the essential infrastructure and workforce, 3) the ability to perform surgery safely under appropriate anaesthesia and finally, 4)affordability ${ }^{[5]}$. Only $54 \%$ of the hospitals have set protocols for triage. In $30 \%$ of the hospitals, the casualty medical officers are the only physicians available to provide resuscitation. Their level of training and experience in providing life support is not uniform. The concept and practice of forming dedicated trauma-response teams is yet to percolate beyond tertiary-care hospitals ${ }^{[6]}$. Singapore uses a four-category system with the first three referring to a range of emergency acuities (priority 1 for resuscitative care, priority 2 for rapid care, priority 3 for urgent care in an ambulatory setting), and the fourth category referring to nonurgent care ${ }^{[7]}$.

Government of Tamil Nadu have initiated a new program to reduce the mortality and morbidities in the name of " Tamil Nadu Accident and Emergency Care Initiative (TAEI)" in the year 2016 with the tagline" Saving Lives is Our Mission'. In India, Tamil Nadu is the only state to undertake accident and emergency care initiative in 2016. Under TAEI, there will be four levels of trauma care centres each one is categorised based on their infrastructure and availabilities of specialists.

Level 1 trauma care centre: The services of all major super specialities associated with trauma care will be available $24 \times 7$. These should be tertiary care centres to which patients requiring highly specified medical care are referred.

Level 2 trauma care centre: It provides definitive care for severely traumatised patients immediately on arrival. It has on call facilities for neurosurgeons, paediatricians, if neurosurgeons are not available general surgeons trained in neurosurgery for a period of 6 months in eminent institutions would be made available $24 \times 7$. The existing medical college hospitals or hospitals with bed strength of 30 to 50 should be identified as level II care centres.

Level 3 trauma care centre: Facility provides initial evaluation and stabilization to the trauma patients. Physicians, orthopaedic surgeons and anaesthetists would be available round the clock. Such hospitals will have limited intensive care facility, diagnostic capacity, blood bank and other supportive services. The district/ taluk hospitals with a bed capacity of 10 to 20 beds would be selected for level III care centre.

Level 4 trauma care centre: This would be appropriately equipped mobile ambulance services. These shall be provide by 108 integrated National Highway Authority of India ambulances in co-ordination with 108 AS NHAI/ NRHM/ State government etc., the patients are referred accordingly to the appropriate level of trauma care centres after proper first aid and stabilizing critically traumatised patients and medical emergencies within golden hour, thereby providing a longer window for survival and reduces complications. The 6 pillars of TAEI and the TAEI logo is shown in Figure I.

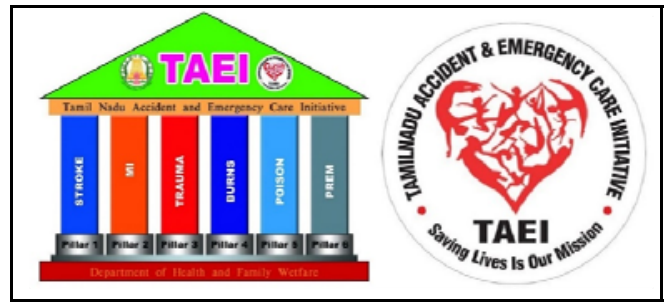

Fig 1: Six pillars of TAEI and TAEI logo.

Triage criteria for TAEI is categorised into 1. Red criteria: patients who need intensive care 2. Yellow criteria: patients who need admission and 3. Green criteria: patients who can be managed as outpatients. With the help of the categorisation we could concentrate more on the intensive care patients in their golden hour. This study was conducted with the aim to analyse the impact of the TAEI programme on orthopaedic surgical fracture fixation and trauma care in our hospital and also to analyse the role of The Tamil Nadu Chief Minister Comprehensive Health Insurance Scheme (CMCHIS) among orthopaedic patients.

\section{Materials and Methods}

This study was conducted in the Institute of Orthopaedics and Traumatology, Government Coimbatore medical college and hospital, Coimbatore. The period of study was from January 2017 to November 2019. The TAEI was implemented at our hospital from June 2018. It is a comparative study. The emergency orthopaedic trauma patients treated before implementation of TAEI in 2017(January -November) was analysed with after implementation of TAEI in 2019(January -November). We also compared the performance of the CMCHIS before and after the implication of the TAEI programme. Our institution is a tertiary care centre where the treatment is given completely free of cost, irrespective of the availability of the health insurance scheme card by the patient. The CMCHIS card is given to the people below poverty line to meet their health care needs in emergencies and other ailments. In the trauma ward we used to get two types of fractures namely open fractures and closed fractures. In our country the two wheeler accidents are the most common mode of trauma injury where the tibial fractures (leg bone) are the commonest, hence we want to fix the fracture with closed intra medullary interlocking nailing and the patient will be shifted to post-operative orthopaedic ward within 6 hours. In the case of open fractures, the wound will be debrided and the long bones will be stabilised with external fixation and the patient will be shifted to plastic surgery ward for raw area cover on the same day. Earlier in 2016 for the open fractures, the wound will be debrided and the fracture will be stabilised mostly with plaster of Paris and the definitive fixation for the fracture was done in elective operation theatre later. The emergency orthopaedic procedures done includes intra medullary nailing of long bones, bone plating, tension band wiring, cerclage, screw fixation, external fixator application, $\mathrm{k}$ wire fixation, Achilles and quadriceps tendon repairs as major cases. Wound debridement, cast applications, skeletal pin traction applications, simple incision drainage, arthrocentesis are minor procedures. After TAEI implementation, there is a separate emergency orthopaedic theatre for orthopaedic procedure with all the facilities like $\mathrm{C}$-arm, orthopaedic operation theatre table, autoclave for orthopaedic implants and instrumentation set are available in TAEI zone itself in our institution which is functioning round the clock. The 
emergency operation theatre staffs were utilised for the orthopaedic theatre procedures without extra manpower. In case of any technical difficulties likeCarm repair, the situation is managed by utilising the $\mathrm{C}$ arm available in main operative theatre. The surgical orthopaedic fixation are done within 6 hours of admission and transferred to orthopaedic ward.

\section{Results}

The total emergency surgeries done before the TAEI implementation in 2017 were 732 cases and total emergency surgeries done after TAEI implementation in 2019 were 1053 patients (Table I; Graph I).

Table 1: Orthopaedic Surgeries done in emergency theatres before and after TAEI implementation.

\begin{tabular}{|c|c|c|c|c|c|c|c|c|c|}
\hline \multirow{2}{*}{ Month } & \multicolumn{3}{|c|}{ 2017(Before TAEI) } & \multicolumn{3}{c|}{$\mathbf{2 0 1 8}$} & \multicolumn{3}{c|}{ 2019 (After TAEI) } \\
\cline { 2 - 11 } & Major & Minor & Total & Major & Minor & Total & Major & Minor & Total \\
\hline JANUARY & 42 & 51 & 93 & 63 & 24 & 87 & 68 & 29 & 97 \\
\hline FEBRUARY & 28 & 32 & 60 & 49 & 16 & 65 & 75 & 17 & 92 \\
\hline MARCH & 20 & 33 & 53 & 65 & 14 & 79 & 92 & 35 & 127 \\
\hline APRIL & 28 & 22 & 50 & 58 & 12 & 70 & 59 & 40 & 89 \\
\hline MAY & 42 & 30 & 72 & 58 & 10 & 68 & 56 & 33 & 89 \\
\hline JUNE & 30 & 30 & 60 & 47 & 15 & 62 & 78 & 20 & 98 \\
\hline JULY & 44 & 34 & 78 & 60 & 30 & 90 & 47 & 36 & 83 \\
\hline AUGUST & 31 & 46 & 77 & 58 & 50 & 108 & 70 & 43 & 113 \\
\hline SEPTEMBER & 43 & 25 & 68 & 58 & 54 & 112 & 32 & 46 & 78 \\
\hline OCTOBER & 37 & 39 & 76 & 60 & 49 & 109 & 63 & 47 & 110 \\
\hline NOVEMBER & 28 & 17 & 45 & 70 & 42 & 112 & 37 & 40 & 77 \\
\hline JANUARY & 373 & 359 & 732 & 646 & 316 & 962 & 677 & 386 & 1053 \\
\hline P value & \multicolumn{9}{|c|}{} \\
\hline
\end{tabular}

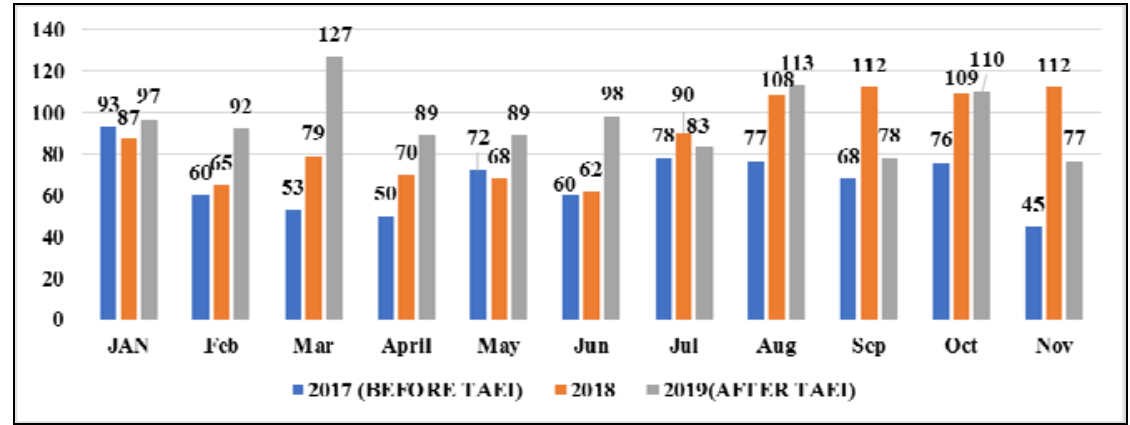

Graph 1: Emergency orthopaedic surgeries done before and after TAEI implementation.

Before TAEI implementation from January 2017 to November 2017, the total number of major orthopaedic operations done in emergency orthopaedic theatre were 373 and after implementation of TAEI from January 2019 to November 2019 the total number of major orthopaedic emergency surgeries done in emergency orthopaedic theatre were 677 at our institution. Before implementation of TAEI in 2017, the total number of intramedullary interlocking nailing done in emergency orthopaedic theatre were only 5 cases, whereas after the implementation of TAEI in 2019 it was 155 patients with an average of 11 nailing procedures per month which is statistically significant (P value 0.00009$)$. The total number of external fixator done in 2017 were 119 whereas after the implementation of TAEI the external fixator applied were 184 cases which is statistically significant (P value0.0009) (Table II; Graph II and III).The overall difference in total emergency operation theatre cases done before and after TAEI implementation is also statistically significant ( $\mathrm{P}$ value 0.0068 ).

Table 2: Total number of intra medullary nailing and external fixation done in emergency OT.

\begin{tabular}{|c|c|c|c|c|c|c|}
\hline \multirow[t]{2}{*}{ Month } & \multicolumn{3}{|c|}{ Intramedullary interlocking nail } & \multicolumn{3}{|c|}{$\begin{array}{l}\text { External fixator application } \\
\end{array}$} \\
\hline & 2017(Before AEI) & 2018 & 2019(After TAEI) & 2017(Before TAEI) & 2018 & 2019(After TAEI) \\
\hline JANUARY & 0 & 1 & 20 & 10 & 17 & 19 \\
\hline FEBRUARY & 0 & 0 & 27 & 10 & 18 & 15 \\
\hline MARCH & 0 & 2 & 24 & 12 & 12 & 17 \\
\hline APRIL & 0 & 2 & 8 & 15 & 15 & 16 \\
\hline MAY & 2 & 0 & 11 & 8 & 17 & 18 \\
\hline JUNE & 1 & 0 & 15 & 15 & 13 & 28 \\
\hline JULY & 0 & 8 & 7 & 11 & 9 & 9 \\
\hline AUGUST & 0 & 10 & 13 & 12 & 13 & 20 \\
\hline SEPTEMBER & 1 & 14 & 6 & 8 & 18 & 15 \\
\hline OCTOBER & 1 & 11 & 14 & 9 & 14 & 15 \\
\hline NOVEMBER & 0 & 14 & 10 & 9 & 18 & 12 \\
\hline Sum & 5 & 62 & 155 & 119 & 164 & 184 \\
\hline P value & \multicolumn{3}{|c|}{.00009} & \multicolumn{3}{|c|}{.0009} \\
\hline
\end{tabular}




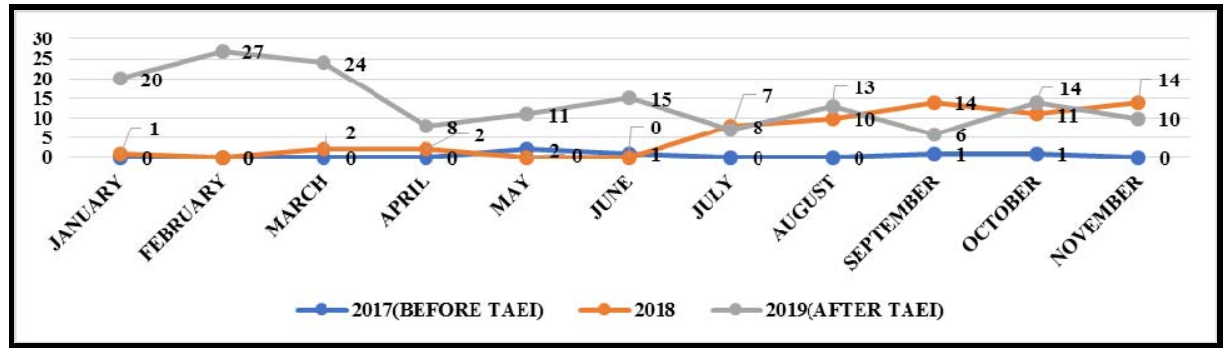

Graph 2: Total number of interlocking nailing done in emergency OT comparison

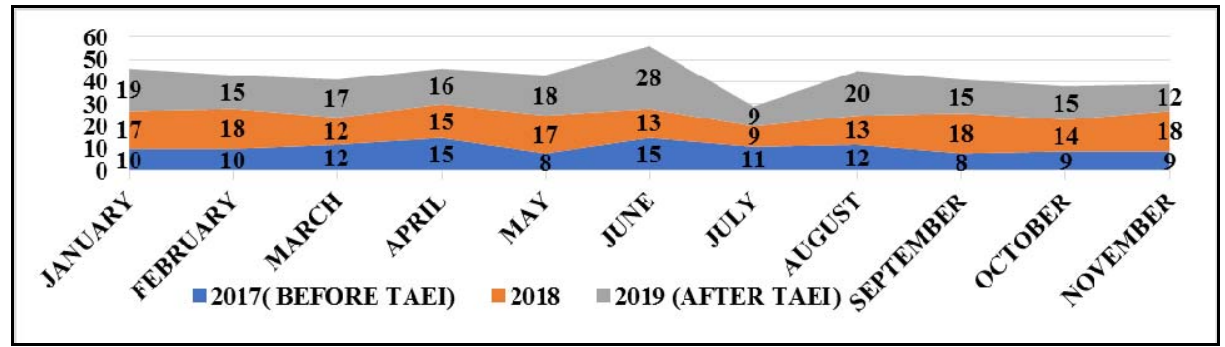

Graph 3: Total number of external fixator application done in emergency OT comparison.

In our institute the bed occupancy in orthopaedic inpatient ward was also reduced after the implementation of TAEI because of reduced hospital stay of the patient as the definitive procedure is done on the day of admission itself. Before implementing TAEI it was 89 per 100 beds per month in male ortho ward and 38 per 56 beds per month in female ortho ward and after implantation of TAEI it was reduced to 82 per 100 beds per month and 32 per 56 beds per month in male and female ortho ward respectively which is statistically significant ( $\mathrm{P}$ value of. 03 for male ortho ward and. 004 for female ortho ward) (Table III; Graph V).

Table 3: Male and female orthopaedic ward average bed occupancy before and after TAEI implementation.

\begin{tabular}{|c|c|c|c|c|}
\hline \multirow{2}{*}{ Month } & \multicolumn{2}{|c|}{ Male Ortho ward (Avg pts/ 100 beds) } & \multicolumn{2}{c|}{ Female Ortho ward (Avg pts/ 56 beds) } \\
\cline { 2 - 5 } & Before TAEI & After TAEI & Before TAEI & After TAEI \\
\hline January & 86 & 80 & 40 & 43 \\
\hline February & 98 & 92 & 41 & 39 \\
\hline March & 85 & 89 & 35 & 31 \\
\hline April & 90 & 84 & 44 & 31 \\
\hline May & 95 & 90 & 41 & 33 \\
\hline June & 93 & 93 & 40 & 31 \\
\hline July & 88 & 89 & 33 & 30 \\
\hline August & 90 & 80 & 38 & 27 \\
\hline September & 86 & 76 & 35 & 20 \\
\hline October & 83 & 64 & 38 & 32 \\
\hline November & 92 & 82 & 38 & .004 (Two tailed paired t-Test) \\
\hline Average & 89 & \multicolumn{2}{c}{} \\
\hline P Value & .03 (Two tailed paired t-Test) &
\end{tabular}

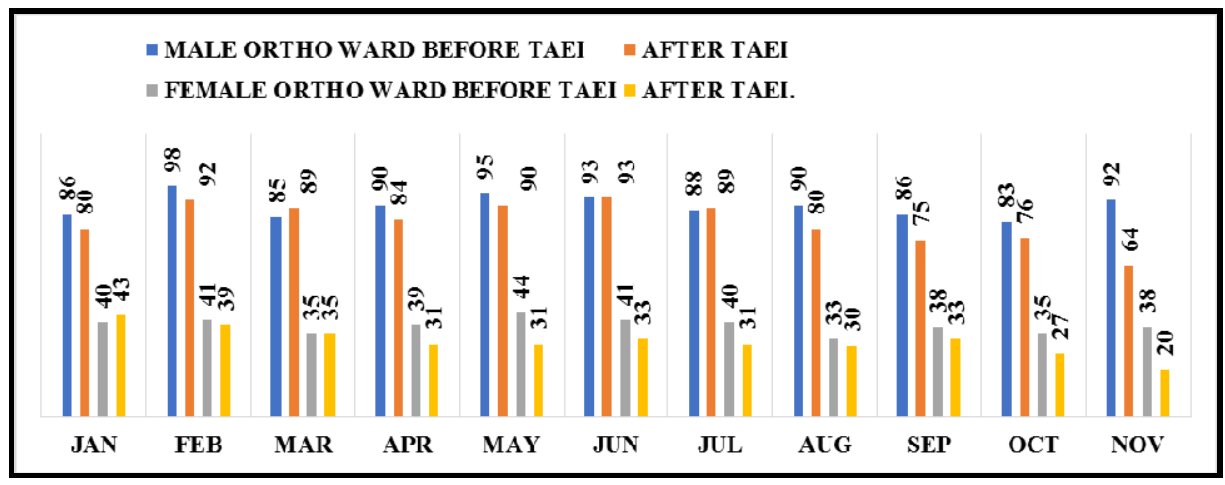

Graph 4: Male and female orthopaedic ward average bed occupancy before and after TAEI

The total number of patients benefitted from the CMCHIS health insurance schemes is also increased after the TAEI implementation. The total number of beneficiaries from the
CMCHIS before TAEI implementation in 2017 were 558 whereas after TAEI implementation in 2019 it was 975 (Table IV; Graph IV). 
Table 4: Total number of claimed insurance status before and after TAEI implementation.

\begin{tabular}{|c|c|c|c|}
\hline \multirow{2}{*}{ Month } & \multicolumn{3}{|c|}{ Total Number of claims } \\
\cline { 2 - 4 } & $\mathbf{2 0 1 7}$ (Before TAEI) & $\mathbf{2 0 1 8}$ & $\mathbf{2 0 1 9}$ (After TAEI) \\
\hline January & 24 & 75 & 75 \\
\hline February & 44 & 100 & 25 \\
\hline March & 24 & 84 & 43 \\
\hline April & 86 & 73 & 71 \\
\hline May & 7 & 66 & 39 \\
\hline June & 76 & 76 & 132 \\
\hline July & 36 & 86 & 207 \\
\hline August & 40 & 53 & 152 \\
\hline September & 100 & 93 & 86 \\
\hline October & 54 & 163 & 80 \\
\hline November & 67 & 85 & 65 \\
\hline Total & 558 & 954 & 975 \\
\hline
\end{tabular}

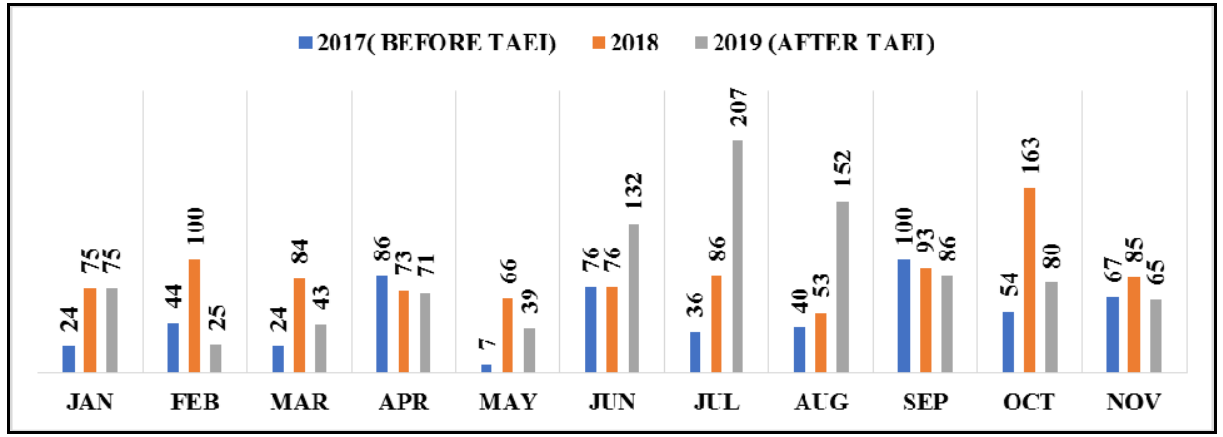

Graph 5: Number of insurance claimed before and after TAEI implementation

\section{Discussion}

Emergency departments (EDs), by their very name, conjure impressions of high acuity, intense action and fast pace of patient care. Most persons would presume that such units are meant for the management of the acutely sick and injured ${ }^{[8]}$. Worldwide, most such departments are generally known to be open to members of the public 24 hours a day. EDs also generally have the potential availability of access to all the resources of the parent hospital at their disposal, such as radiological services and other investigative modalities, in addition to an almost unlimited array of pharmaceuticals ${ }^{[6]}$. A key principle of provision of an acute surgical service is establishment of an efficient emergency theatre dedicated to acute surgery ${ }^{[9]}$.

In our hospital, the emergency operation theatre, emergency radiological services and blood investigation lab are situated very near to the TAEI zone. Moreover TAEI is having an exclusive emergency orthopaedic state of art operation theatre with laminar airflow facility, C-arm image intensifier, implants and instrumentation sets which are readily available round the clock (Figure II)

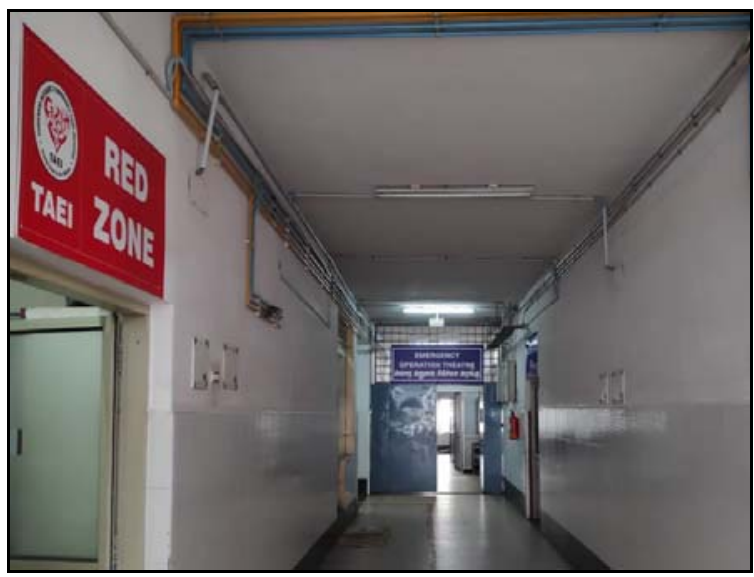

Fig 2: Emergency operation theatre nearby to the TAEI zone.

The rationale behind establishing emergency theatres includes improving the ease of access to theatre for acute surgery and to cut-down on the amount of unnecessary out of hours emergency surgery being conducted when there are limited numbers of staff available ${ }^{[10]}$.

Normally the patient from outpatient department (OPD) or casualty will be admitted and transferred to orthopaedic ward. From there, the blood investigations will be sent to biochemistry lab. Then the reports will be collected from the lab. On the next day the patient is sent for specialists opinion especially cardiology for echocardiography evaluation from ward based on the necessity. After the cardiology opinion and 
other specialist's opinion, fracture patient will be sent for assessment or anaesthetist will be called over to ward for assessment for surgery. This process may take nearly 3-7 days normally. The TAEI has its impact on the hospital stay by decreasing the duration of stay since the definitive procedure being done in emergency theatres and patient is transferred to post-operative ward within 6 hours of admission. Hence the patient will be discharged after 3-5 days of surgery (Table V).

Table 5: Advantage of TAEI over elective surgical fracture fixation in Government setup.

\begin{tabular}{|c|c|c|}
\hline & TAEI & Elective \\
\hline Blood investigation & $\begin{array}{c}\text { Sent to 24 hours lab and results } \\
\text { obtained within an hour }\end{array}$ & Sent to routine lab and collection of results from ward \\
\hline Radiology investigations & Immediately taken within an hour & Patient Sent to radiology department from ward \\
\hline Cardiac evaluation & Immediately obtained & Patient Sent to echo lab for evaluation \\
\hline Anaesthetic assessment & Immediately obtained in TAEI ward & $\begin{array}{c}\text { Patient Sent to assessment clinic from ward or anaesthetist } \\
\text { call over to ward for assessment }\end{array}$ \\
\hline CMCHIS status & $\begin{array}{c}\text { Emergency insurance number (E. No) } \\
\text { obtained }\end{array}$ & $\begin{array}{c}\text { Insurance personnel has to confirm and process the scheme in } \\
\text { ward. }\end{array}$ \\
\hline $\begin{array}{c}\text { Orthopaedic Surgical fracture } \\
\text { fixation }\end{array}$ & Done immediately within 6 hours \\
\hline $\begin{array}{c}\text { Surgery time delay from admission } \\
\text { time (in days) }\end{array}$ & Nil & $\begin{array}{c}\text { The patient posted in elective surgery list as peniority } \\
\text { based on Inpatient number (IP no) }\end{array}$ \\
\hline Post-operative Hospital stay period & 3-5 DAYS & 10-14 DAYS \\
\hline
\end{tabular}

If the compound fractures are not stabilised without proper alignment it may end up in non-union or malunion deformity even after flap cover for raw area. Hence in our institute, the compound fractures are well aligned and fixed with external fixator under $\mathrm{C}$-arm image intensifier support and are transferred to the plastic surgery department for any raw area flap cover or skin grafting procedures on the day of admission for immediate secondary procedures (Figure III).

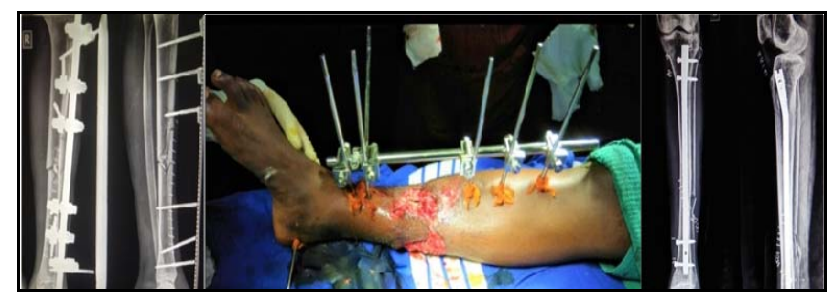

Fig 3: A well aligned compound fracture tibia fixed with external fixator is ready for raw area cover and intramedullary nailing done for closed tibial fracture.

The performance of the emergency orthopaedic procedures were at par with the corporate hospitals both in terms of quantity and quality at our institution after the TAEI programme implementation. Entire inpatient orthopaedic ward is under CCTV surveillance which had created a sense of threat for the agents who motivate patients for treatment in private hospitals. Surprisingly the number of patients going for against medical advice (AMA) in trauma ward was phenomenally decreased after this programme.

Before the TAEI program, Tertiary care Government hospitals were utilized as a hub to take away the patients to private hospitals by the agents, informing the relatives of the victim that it will take time for surgical fixation in Government hospitals. It created a very big financial strain to the accident victim's family. By doing orthopaedic surgical fixation free of cost by the Government of Tamil Nadu on the day of admission, the private agent's motivation for personal gain is stopped. Moreover the financial burden to the people below poverty line is more or less nil. When any human being is fractured, the whole family will be not only with financial strain but also with mental agony since their day to day routine activity is affected in order to take care of the fractured patients. By reducing the hospital stay the patient as well as the family will go back to their home without much financial strain. By providing facilities like 24 hours purified water facility, good sanitation, air-conditioning in the postoperative ward and installation of LED Television for IEC activities in our orthopaedic institute are the few facilities provided in the orthopaedic ward (Figure IV and V).

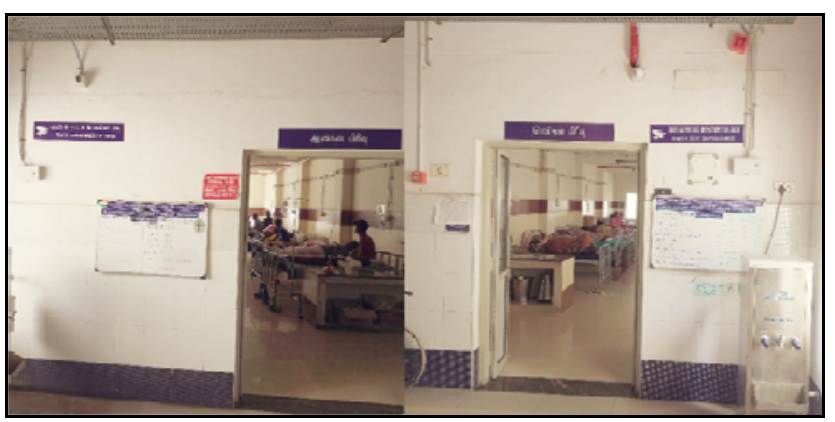

Fig 4: CCTV camera surveillance and water purifier in male and female orthopaedic inpatient ward

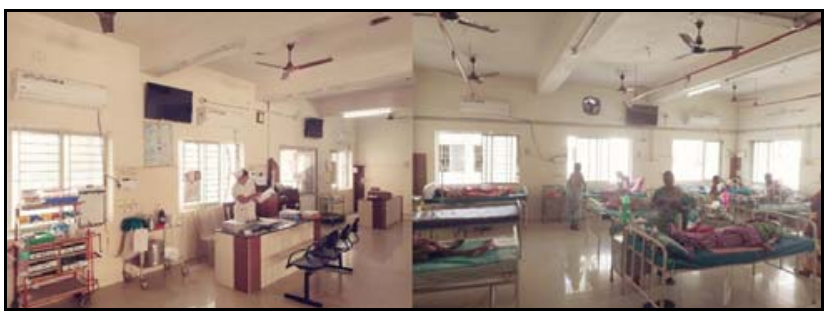

Fig 5: Air conditioner units and LED televisions installed in post-operative ward.

Most of the attenders are Geriatric patients and we are providing attender cot for them in a phased manner. Hence the TAEI implementation has a major role in improving patient care and strengthening our hospital services.

The success of this programme is because of the following reasons

1. Adequate implant position provided by the Government of Tamil Nadu.

2. Utilising the available instruments and equipment like $\mathrm{C}$ arm, top quality power drills, autoclave and separate orthopaedic theatre room (Figure VI). 


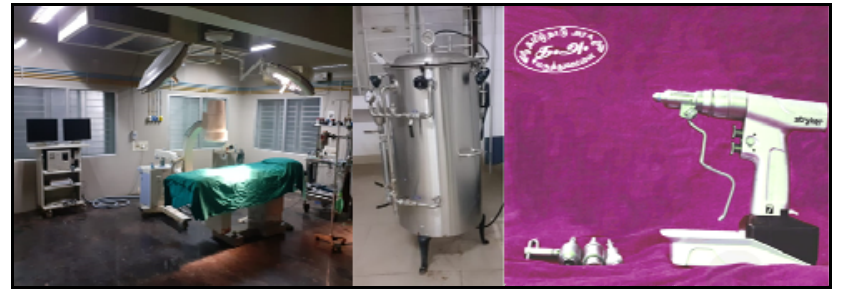

Fig 6: Dedicated Orthopaedic OT room with $\mathrm{C}$ arm and separate autoclave and advanced drill set.

3. The entire orthopaedic, anaesthetic, nursing and paramedical group work as a team in a coordinated manner by utilised the available manpower in a productive way without extra manpower by the Government of Tamil Nadu helped in achieving this goal.

The steps for successful implementation of the programme is shown in Figure VII.

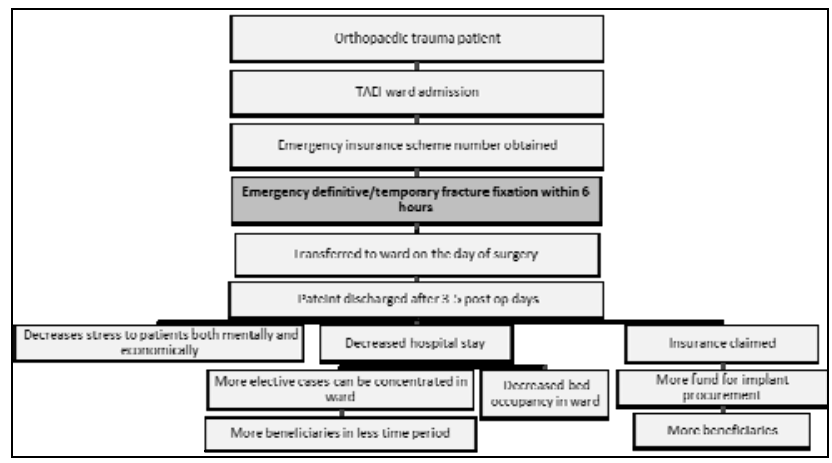

Fig 7: Success steps of the programme implementation

Even though the trauma care was given at free of cost before the implementation of TAEI, after its implementation it helped the Tamil Nadu Government not only in maintaining its quality health care but also financially by treating the patients under CMCHIS there by generating more fund which can be used for improving the infrastructure, drugs, consumables and purchasing state of art equipment and instruments for the patient health care which was not possible before the CMCHIS implementation.

Before the CMCHIS implementation the health department was an expenditure department whereas after the CMCHIS it has become an earning department as the beneficiaries are increased because of more patients getting treated under CMCHIS programme. In our institute of orthopaedics and traumatology from the fund generated under CMCHIS, the Government of Tamil Nadu have provided a high end quality $\mathrm{C}$-arm machine (Figure VIII) in the operation theatre.

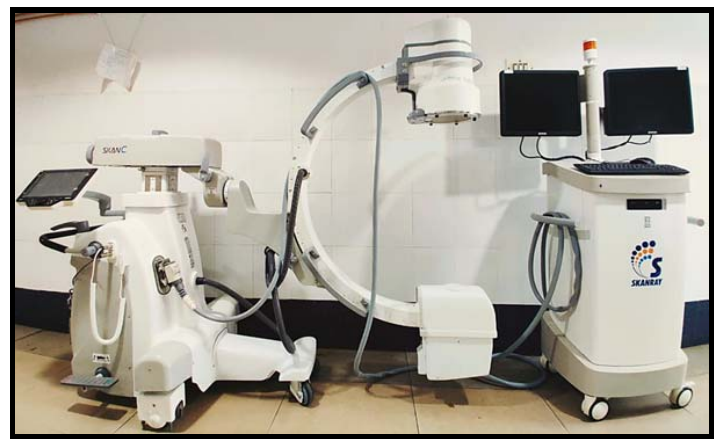

Fig 8: High end quality $\mathrm{C}$-arm machine.

\section{Conclusion}

In India, Tamil Nadu is the role model for health care delivery system. TAEI is an undoubtedly pioneer initiative in trauma and emergency care provided at free of cost by the Government of Tamil Nadu, which can be followed in other government health centres in low income countries for meeting the difficulties in the emergency departments and trauma care to the patients by increasing the immediate orthopaedic fixation and by decreasing the hospital stay rather spending huge money in corporate hospitals.

Moreover the CMHIS have provided a face lift to the Government hospital as per our study by the way of generation of fund which can be used as a role model for better health care delivery in low income countries.

\section{References}

1. WHO South East Asia Regional Office, SCN Department, New Delhi (2001) Disability, Violence Injury, Prevention and Rehabilitation. Newsletter, 2001, $2(1)$.

2. Gururaj G. Injuries in India: National Perspective Burden of Disease in India National Commission on Macroeconomics and Health Government of India. 2005, 325-347.

3. Meara JG, Leather AJ, Hagander L, Alkire BC, Alonso $\mathrm{N}$, Ameh EA, et al. Global surgery 2030: Evidence and solutions for achieving health, welfare, and economic development. Lancet. 2015; 386:569-624.

4. World Health Organization. 68th World Health Assembly. Strengthening Emergency and Essential Surgical Care and Anaesthesia as a Component of Universal Health Coverage. Available from: http://www.apps.who.int/gb/ebwha/pdf_files/WHA68/A6 8_R15-en.pdf). [Last accessed on 2017 Dec 17].

5. Kant L, Roy N, Zodpey SP. Surgical conditions - A neglected aspect of public health: Call to action. Indian J Public Health. 2018; 62:211-3.

6. Joshipura MK. Trauma Care in India: Current Scenario, World J Surg. 2008; 32:1613-1617. DOI 10.1007/s00268-008-9634-5.

7. Anantharaman V. Impact of health care system interventions on emergency department utilization and overcrowding in Singapore, Int $\mathrm{J}$ Emerg Med. 2008; 1(1):11-20. Published online 2008 Mar14. doi: 10.1007/s12245-008-0004-8

PMCID: PMC2536176.

8. Steinbrook R. The role of the emergency department. N Engl J Med. 1996; 334:657-658. doi: 10.1056/NEJM199603073341010. [PubMed] [Cross Ref] [Google Scholar].

9. Addison PDA, Getgood S. Paterson-Brown, Separating elective and emergency surgical care (the emergency team), Scott Med. J. 2001; 46(2):48e50.

10. O'Leary DP, Beecher S, McLaughlin R. Emergency surgery pre-operative delays- Realities and economic impacts, International Journal of Surgery. 2014; $12: 1333 \mathrm{e} 1336$. 